Classification

Physics Abstracts

81.30B $-61.16 \mathrm{~F}$

\title{
The miscibility gap in the FeBe system
}

\author{
Michael K. Miller $\left({ }^{1}\right)$ and Mary Grace Burke $\left({ }^{2}\right)$ \\ ( $\left.{ }^{1}\right)$ Metals and Ceramics Division, Oak Ridge National Laboratory, Oak Ridge, TN 37831-6376, \\ U.S.A. \\ (2) Westinghouse Science and Technology Center, Pittsburgh, PA 15235, U.S.A.
}

(Received 24 June 1992; accepted October 13, 1992)

\begin{abstract}
The technique of atom probe field ion microscopy has been used to estimate the position of the low temperature miscibility gap in the iron-rich portion of the iron-beryllium system by direct measurement of the compositions of the phases. The morphology of the two phases produced by spinodal decomposition within this miscibility gap was determined to be a dislocated macrolattice of isolated cuboidal particles of the iron-rich $\alpha$ phase embedded in a matrix of the B2-ordered berylliumenriched $\mathrm{FeBe}$ phase. Atom probe measurements indicated that there was a significant variation in the compositions of the coexisting phases and the differences in the beryllium contents between the phases increased with aging time at 350 and $400^{\circ} \mathrm{C}$.
\end{abstract}

\section{Introduction.}

The iron-rich portion of the iron-beryllium system is of interest since it contains a low temperature miscibility gap that is intersected by a disorder to order transformation. Within this low temperature miscibility gap, the supersaturated body centered cubic solid solution decomposes into a mixture of an iron-rich body centered cubic (A2) $\alpha$ phase and a beryllium-enriched B2-ordered $(\mathrm{CsCl}) \mathrm{FeBe}$ phase. This decomposition produces a modulated microstructure in which concentration fluctuations are observed along orthogonal $\langle 001\rangle$ directions. Incorporating the data of Heubner [1] and Richman and Davies [2], Higgins et al. constructed a solvus for this metastable miscibility gap over the temperature range 380 to $500^{\circ} \mathrm{C}$, as shown by the dashed line in figure 1 . These results indicated that the critical temperature was slightly below $460^{\circ} \mathrm{C}$ and at $\sim 19$ at. \% $\mathrm{Be}$ [3]. In this paper, an estimate of the extent of the miscibility gap is presented based on the direct measurement of the compositions of the coexisting phases.

The compositions of the two phases in this modulated microstructure are extremely difficult to analyze experimentally by direct methods such as analytical electron microscopy due to their ultrafine scale and the low atomic number of beryllium. In principle, the atom probe field ion microscope (APFIM) should be well suited to this type of analysis due to its near atomic spatial resolution in analysis and its ability to characterize the concentration of all elements [4]. The magnitude of the problem of measuring the compositions of these phases may be put in perspective by considering the scale of the modulated microstructure. The wavelength of the microstructure has 


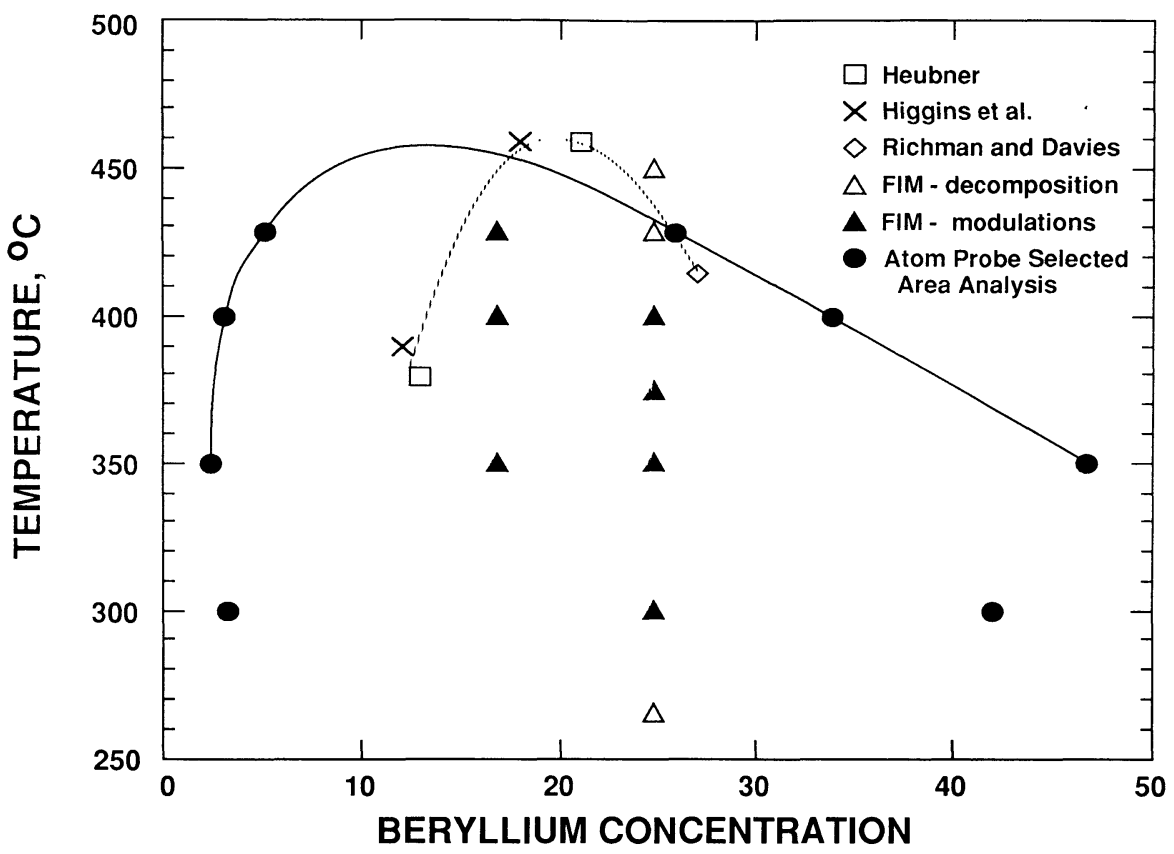

Fig. 1. - Phase diagram of the iron-rich portion of the iron-beryllium system. The filled triangles represent field ion microscopy identification of a modulated microstructure, the open triangles represent phase decomposition detected by either field ion microscopy or atom probe analysis. The solid circles are the atom probe selected area analysis determinations of the maximum compositions of the phases. Other symbols refer to prior work as described in text and insert.

been previously estimated from both the position of the sidebands in electron diffraction patterns and from the spacing of the modulations in the field ion image [5]. These results indicated that the wavelength of the modulations increased from only 4.3 to $15.7 \mathrm{~nm}$ for Fe-25\% Be material aged at $350^{\circ} \mathrm{C}$ for 2 and $149 \mathrm{~h}$, respectively. The time exponent of the coarsening of this microstructure was determined by fitting these wavelength data to a $t^{a}$ power law with $a=0.30$ and a goodness of fit of $R=0.998$. A similar range of wavelength values was obtained for material aged between $20 \mathrm{~min}$. and $4 \mathrm{~h}$ at $400^{\circ} \mathrm{C}$. If it is assumed that 1 ) there is an equal volume fraction of both phases (this is equivalent to assuming that the compositions of the coexisting phases are pure iron and equiatomic FeBe for the 25 at.\% Be alloy) and 2) that the iron-rich phase is in the form of small cubes embedded in a matrix of the B2-ordered phase, then the size of the iron-rich phase cubes is $80 \%$ of the wavelength and the "thickness" of the B2-ordered phase is $20 \%$ of the wavelength. Therefore, the total number of atoms in an average cube of the iron-rich phase ranges from approximately 350 to 160,000 for these aging treatments. In atom probe analysis, where atoms are only collected from a cylinder of material sampling the cube and taking into account the detection efficiency of the mass spectrometer (typically $\sim 65 \%$ ), these numbers of atoms are reduced to approximately 100 and 360 , respectively. The number of atoms could be increased by taking the cylinder of analysis along the [110] (cylinder B) or [111] directions. However, the orthogonal directions are the only directions in which there is little or no simultaneously sampling of the phases and therefore these directions are to be preferred. The numbers of atoms from the B2-ordered phase are only $25 \%$ of these values if the analysis is performed parallel to the [100] direction of the macrolattice, as shown for cylinder $\mathrm{A}$ in figure 2 . It should be noted that these estimates are 
only approximate since the macrolattice of cubes is not perfectly aligned along the $\{100\}$ directions and the iron-rich phase does not form perfect cubes (see below). In addition, the selection of the precise axis of the cylinder of analysis is experimentally difficult, since 1) the macrollatice may have any orientation relationship with the wire axis of the polycrystalline specimen and 2) the axis of the cylinder of analysis is defined by the effective starting position of the probe aperture on the surface of the specimen and the taper angle of the needle-shaped specimen [4]. These factors result in a cylinder of analysis that is more likely to correspond with cylinder $\mathrm{C}$ in figure 2 .

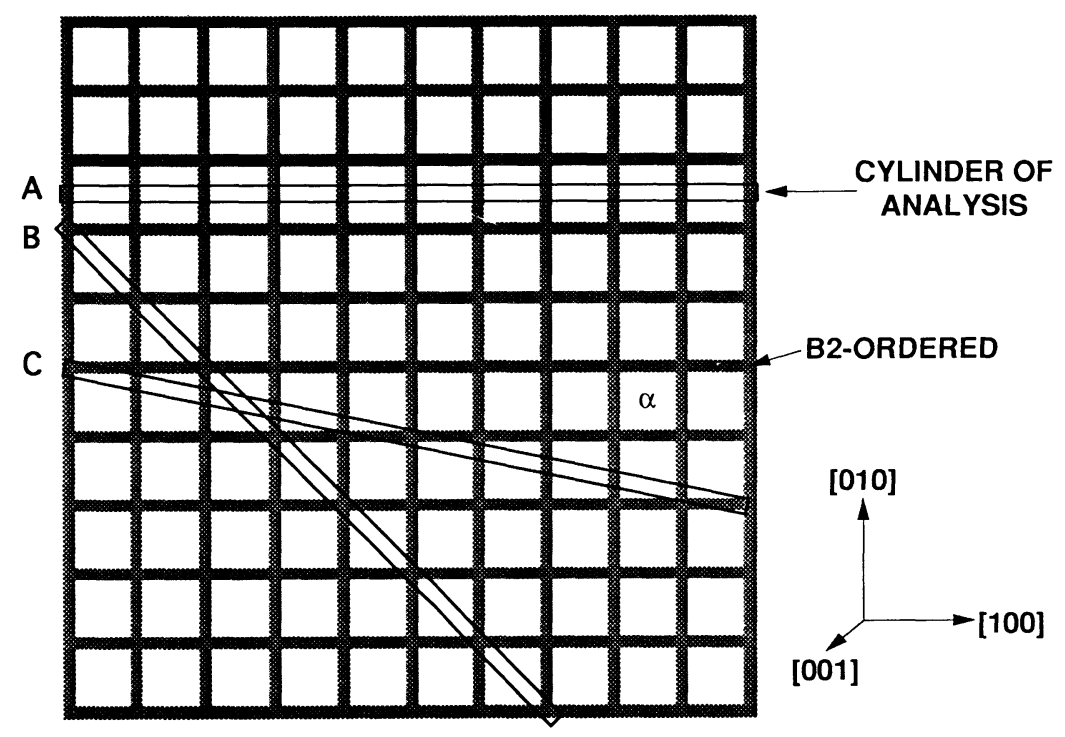

Fig. 2. - Two dimensional schematic diagram of the intersection of the cylinder of anaiysis with a two phase modulated microstructure. Note that the volume fractions of the two phases are equal in the full 3 dimensional representation. Cylinder $\mathrm{A}$ is along the [100] direction and alternately intersects the $\alpha$ and B2-ordered phases with sharp interfaces. Cylinder B is along the [110] direction and alternately intersects the $\alpha$ and B2ordered phases with diffuse interfaces due to simultaneous sampling of the phases. Cylinder $\mathrm{C}$ represents an arbitrary direction typical of an atom probe random area analysis.

\section{Experimental.}

The materials used in this investigation were $\mathrm{Fe}-17$ at. \% $\mathrm{Be}$ and $\mathrm{Fe}-25$ at. \% Be alloys. Standard wet chemical analysis after hot rolling and fabrication into blanks suitable for the production of field ion specimens yielded compositions of Fe- 16.9 at. \% Be- 0.08 at. \% C and Fe- 24.8 at. \% Be- 0.69 at. \% C, respectively. The carbon in the $25 \% \mathrm{Be}$ alloy was found to be associated with coarse $\mathrm{Be}_{2} \mathrm{C}$ carbides with a number density of approximately $10^{3} \mathrm{~cm}^{-3}[6$. It should be noted that the mechanical stages of the fabrication had to be performed prior to the low temperature aging treatments due to the extreme hardness of some of the aged materials. After initial fabrication, all material was solution treated at $1100{ }^{\circ} \mathrm{C}$ for $0.5 \mathrm{~h}$ prior to isothermal aging within the low temperature miscibility gap. The materials were examined after isothermal aging at $265,300,350$, $375,400,429$ and $450{ }^{\circ} \mathrm{C}$ for various times up to $150 \mathrm{~h}$. Unfortunately, decomposition of the 
$\alpha+B 2$ - ordered phases that constitute the modulated microstructure into a mixture of another ferrite and a metastable B32-ordered phase prevented the use of longer aging times to generate a coarser and more easily analyzable microstructure [7].

All atom probe analyses reported in this paper were obtained with the Oak Ridge National Laboratory (ORNL) energy-compensated atom probe field ion microscope. Full details of this instrument are described elsewhere [8]. Under the conditions used in these atom probe experiments (specimen temperature of between 50 and $60 \mathrm{~K}$ and a pulse fraction of greater than $15 \%$ ), the monoisotopic beryllium was found to field evaporate almost exclusively as $\mathrm{Be}^{2+}$ at a mass-tocharge ratio of $4.5 \mathrm{amu}$ and iron as $\mathrm{Fe}^{2+}$ species at mass-to-charge ratios of 27, 28, 28.5 and 29 amu. No deconvolution procedures were necessary due to the wide separation of these species in the mass spectra. All compositions quoted in this paper are in atomic percent. The error bars on the concentration determinations are based solely on the counting statistics of the analysis (i.e. the number of atoms $N$ in the sample) and are given for one standard deviation where $\sigma=\sqrt{(c(1-c)) / N}$. All random area atom probe analysis were performed with a constant effective probe aperture by adjusting the distance of the channel plate and phosphor screen assembly from the specimen during the experiment. From calibration experiments on $\mathrm{Fe}-\mathrm{Cr}$ and $\mathrm{Ni}_{3} \mathrm{Al}$ specimens, the effective diameter of the cylinder of analysis used in these analyses was estimated to be $0.8 \mathrm{~nm}$.

The extent of the concentration fluctuations in the random area atom probe analyses was estimated from three models : the $P_{\mathrm{a}}$ model (a sinusoidal distribution) $[9,10]$ and models based on a square wave distribution and a mixture of two Gaussian distributions. In all models, a block size of $N=30$ atoms was used.

The $P_{\mathrm{a}}$ model considers different samples from a discretized composition profile

$$
p_{j}=P_{\mathrm{o}}+P_{\mathrm{a}} \sin \left(\frac{2 \pi j}{n_{\mathrm{d}}}\right), \quad\left\{j: 0 \leq j<n_{\mathrm{d}}\right\}
$$

where the $2 P_{\mathrm{a}}$ is the peak-to-peak amplitude of the spinodal, $P_{\mathrm{o}}$ is the mean composition and $n_{\mathrm{d}}$ is the discretization, i.e. a number chosen to ensure that the estimate is independent of $n_{d}\left(n_{d}=20\right)$. The likelihood of obtaining $n$ solute atoms in a block of $N$ atoms is

$$
P(n, N)=\frac{1}{n_{\mathrm{d}}} \sum_{j=0}^{n_{\mathrm{d}}}\left(\begin{array}{l}
N \\
n
\end{array}\right) p_{j}^{n} q_{j}^{N-n}
$$

where $q_{j}=1-p_{j}$. The likelihood is maximized by maximizing $S=\log |L|$ with respect to $P_{\mathrm{a}}$ where

$$
S=\log |L|=\sum_{i=0}^{N} O(i) \log |P(i, N)|
$$

and $O(i)$ is the number of times a block containing $i$ solute atoms was experimentally observed. It should be noted that the volume fractions of the two phases are defined to be $50 \%$ in this method.

The atom probe data may also be modeled by a square wave distribution where each amplitude represents the contribution from one of the phases present in the microstructure. The probability distribution function $P(n, N)$ for this distribution in which $n$ type 1 solute atoms are collected in a block containing $N$ atoms may be written as

$$
P(n, N)=a_{1}\left(\begin{array}{l}
N \\
n
\end{array}\right) p_{1}^{n}\left(1-p_{1}\right)^{N-n}+a_{2}\left(\begin{array}{l}
N \\
n
\end{array}\right) p_{2}^{n}\left(1-p_{2}\right)^{N-n}
$$

where $a_{1}$ and $a_{2}$ are the volume fractions of the two phases such that $a_{1}+a_{2}=1$ and $p_{1}$ and $p_{2}$ are the probabilities of obtaining type 1 and 2 atoms, respectively. 
The data may also be modeled by two Gaussian distributions where each distribution represents the contribution from one of the phases present in the microstructure. The probability distribution function $P(c)$ for two Gaussian distributions may be written as

$$
P(c)=a_{1} \frac{\exp \left[\frac{-\left(c-\mu_{1}\right)^{2}}{2 \sigma_{1}^{2}}\right]}{\sigma_{1} \sqrt{2 \pi}}+a_{2} \frac{\exp \left[\frac{-\left(c-\mu_{2}\right)^{2}}{2 \sigma_{2}^{2}}\right]}{\sigma_{2} \sqrt{2 \pi}} .
$$

This function is a double Gaussian distribution, with one Gaussian centered at $\mu_{1}$ and the other at $\mu_{2}$, and with widths $\sigma_{1}$ and $\sigma_{2}$. The number of independent parameters may be reduced by consolidating the widths of the Gaussian distributions $\sigma_{1}$ and $\sigma_{2}$ into a single parameter $\sigma$. In this study, the parameter $\mu_{1}$ refers to the iron-rich $\alpha$ phase and the parameter $\mu_{2}$ to the berylliumenriched B2-ordered phase. The maximum likelihood procedure used to obtain the estimates of the parameters of the square wave and Gaussian models is based on direct maximizing of the logarithm of the likelihood function and uses the Nelder-Mead Simplex subroutine as implemented by Olsson $[11,12]$. All applicable results quoted from these deconvolution procedures have been normalized to atomic percent.

In the variant of the sinusoidal or $P_{\mathrm{a}}$ model used in this study, there is only one parameter, $P_{\mathrm{a}}$, whereas there are three independent fitting parameters $\mu_{1}, \mu_{2}$, and $a_{1}$ in the square wave model and three independent fitting parameters $\mu_{1}, \mu_{2}$, and $\sigma$ in the Gaussian model. The volume fractions in the Gaussian model were calculated from the mean concentrations of the two phases and the mean concentration of the analysis with the use of the lever rule. In both the square wave model and the Gaussian model, the parameter $\mu_{2}-\mu_{1}$ is an estimate of the difference in solute concentration of the two phases, $\Delta c$, and is equivalent to the parameter $2 P_{\mathrm{a}}$.

\section{Results and discussion.}

MORPHOLOGY. - The fine-scale $\langle 100\rangle$ modulated nature of the microstructure that is formed upon aging within the low temperature miscibility gap in shown in figure 3 for the $\mathrm{Fe}-25 \% \mathrm{Be}$ material that was aged for $114 \mathrm{~h}$ at $300^{\circ} \mathrm{C}$. Even though the average wavelength of the modulations in this material was determined to be only $\sim 4.8 \mathrm{~nm}$, the two phase nature of this microstructure is clearly distinguished. The three sets of $\langle 100\rangle$ modulations are apparent as the horizontal, vertical and circular sets of dark bands. Selected area atom probe analysis has revealed that the brightly-imaging regions in these field ion images are the iron-rich $\alpha$ phase and the darkly-imaging regions are the beryllium-enriched B2-ordered FeBe phase. Further confirmation of this identification is that the volume fraction of the darkly-imaging B2-ordered phase was lower in the $17 \%$ Be alloy than in the $25 \%$ Be alloy. The B2-ordering was established from the presence of superlattice reflections in electron diffraction patterns and by detecting the alternating pure iron and pure beryllium planes along the [001] direction in atom probe analyses. A dark field electron micrograph taken with a (100) B2 superlattice reflection is shown in figure 4. A discussion of the interpretation of these modulated microstructures has been reported previously [13]. The morphology of this modulated microstructure is best described as a macrolattice of isolated cuboidal particles of the $\alpha$ phase embedded in a matrix of the B2-ordered phase. Some spheroidization of the $\alpha$ and B2-ordered phases was observed in the longer aging treatments at $400^{\circ} \mathrm{C}$, as shown in figure 5 for the $25 \%$ Be alloy aged for $4 \mathrm{~h}$ at $400^{\circ} \mathrm{C}$. Field ion and transmission electron micrographs of this modulated microstructure have revealed that there is a significant deviation from a perfect orthogonally aligned macrolattice [14]. These observations suggest that the microstructure coarsens by the dissolution of unfavorably located iron-rich $\alpha$ phase particles in the "dislocated" macrolattice. 


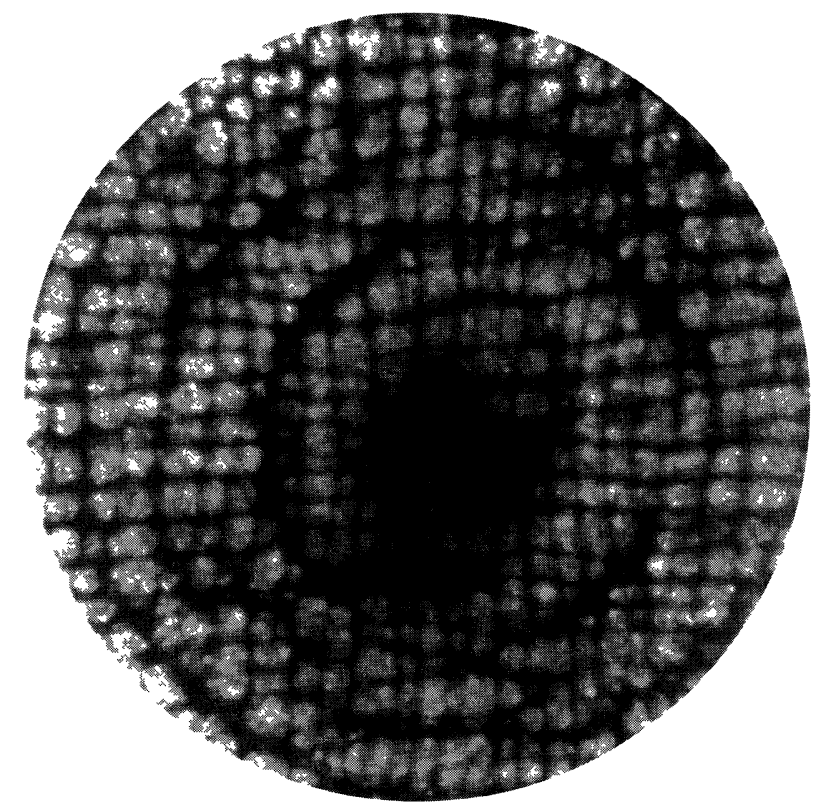

Fig. 3. - Field ion micrograph of the modulated microstructure in an $\mathrm{Fe}-25 \%$ Be alloy aged for $114 \mathrm{~h}$ at $300{ }^{\circ} \mathrm{C}$. The three sets of $\langle 100\rangle$ modulations are apparent as the horizontal, vertical and circular sets of dark bands. Selected area atom probe analysis has revealed that the brightly-imaging regions are the iron-rich $\alpha$ phase and the darkly-imaging regions are the beryllium-enriched B2-ordered FeBe phase.

MISCIBILITY GAP. - The $\alpha+$ B2-ordered modulated microstructure was observed in both materials aged for various times at $300,350,375,400^{\circ} \mathrm{C}$ but was not observed after isothermal aging at 450 or $514{ }^{\circ} \mathrm{C}$, as shown in figure 1 . Field ion micrographs of the 17 and $25 \%$ Be alloys aged for $2 \mathrm{~h}$ at $429^{\circ} \mathrm{C}$, shown in figure 6, revealed that the modulated structure was evident in the $17 \% \mathrm{Be}$ alloy but only a low volume fraction isolated brightly-imaging $\alpha$ particles was observed in the $25 \%$ Be alloy. From the lever rule, this observation suggests that the location of the miscibility gap at this temperature is only slightly higher than the nominal beryllium concentration of the $25 \% \mathrm{Be}$ material. Phase separation was also detected in atom probe random area analyses in material that was aged for $100 \mathrm{~h}$ at $256^{\circ} \mathrm{C}$ but was not evident in the field ion images indicating that this time was not sufficient for significant phase separation to have occurred at this low temperature.

The results of selected area analyses of the iron-rich $\alpha$ phase and the beryllium-enriched B2ordered phase are summarized in table $I$. These results are for the longest aging times examined at the particular temperature that exhibited the $\alpha$ plus B2-ordered phase microstructure. For example, all $\mathrm{Fe}-25 \%$ Be specimens examined in the atom probe that were aged for $32 \mathrm{~h}$ at $400^{\circ} \mathrm{C}$ were found to bve a mixture of an iron-rich ferrite and a B32-ordered phase and therefore the results at this temperature were taken from the material aged for $4 \mathrm{~h}$. The $25 \%$ Be material that was aged for $149 \mathrm{~h}$ at $350^{\circ} \mathrm{C}$ was also found to be predominantly a mixture of an iron-rich ferrite and a B32-ordered BeFe phase. However, in this material, some areas of the modulated microstructure were also observed in the field ion microscope, as shown in figure 7. The atom probe selected area analysis results from the $17 \% \mathrm{Be}$ alloy aged for $2 \mathrm{~h}$ at $429^{\circ} \mathrm{C}$ are in good agreement with the volume fraction information from the $25 \% \mathrm{Be}$ material, as indicated in figure $6 \mathrm{~b}$. It is evident from these atom probe results that there are significant variations in the compositions of individual $\alpha$ particles and regions of the B2-ordered phase. It should be noted that the highest beryllium value 


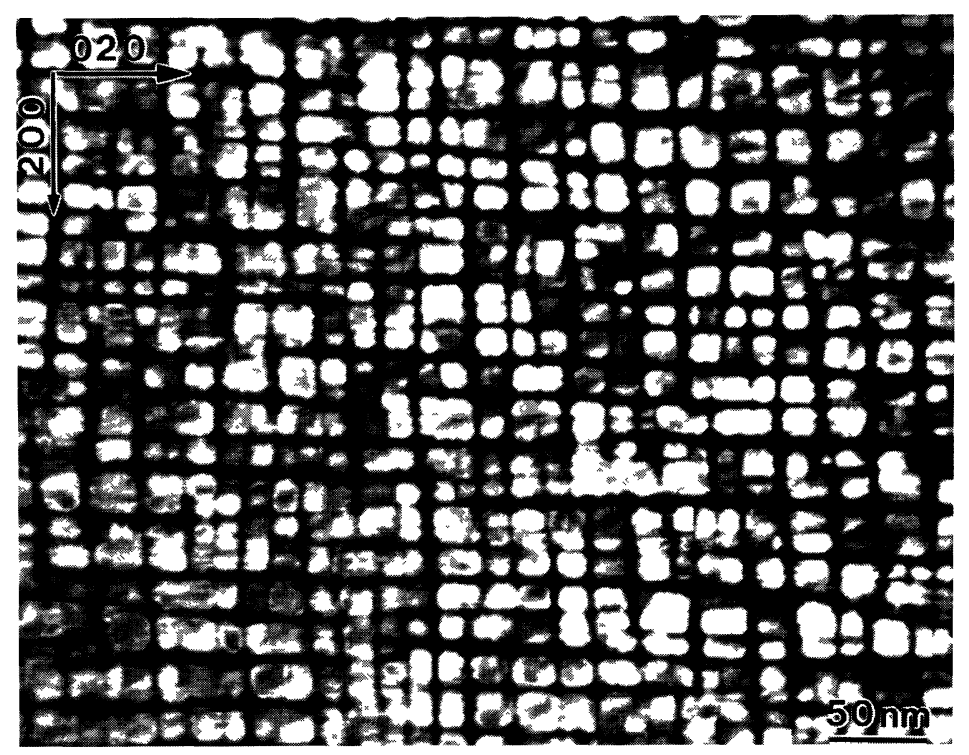

Fig. 4. - Dark field electron micrograph of an Fe- $25 \%$ Be alloy aged for $2 \mathrm{~h}$ at $400{ }^{\circ} \mathrm{C}$ taken with a B2 superlattice reflection showing the modulated microstructure.

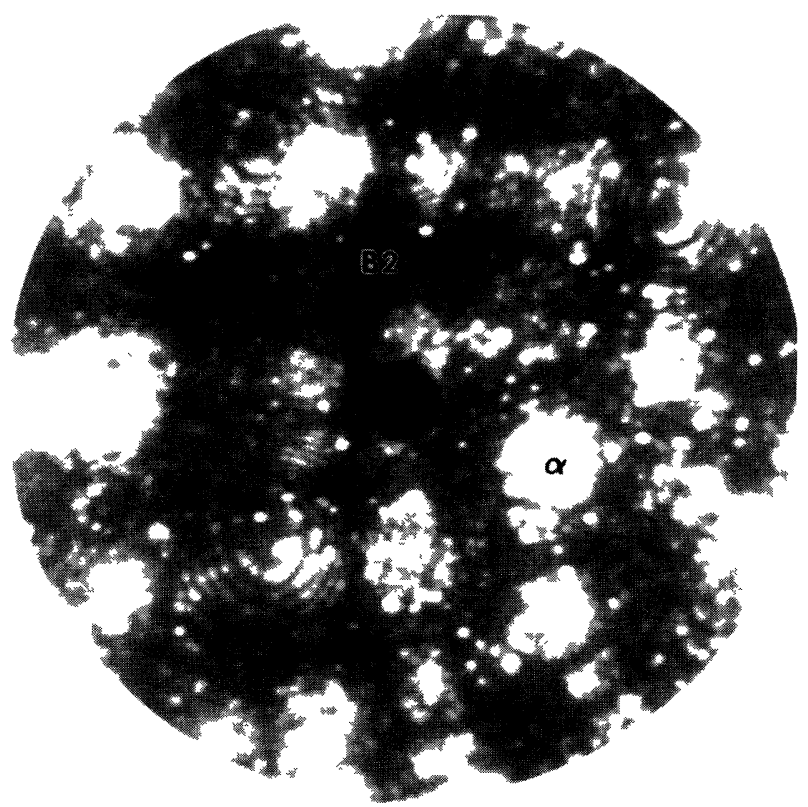

Fig. 5. - Field ion micrograph of the Fe- $25 \%$ Be alloy aged $4 \mathrm{~h}$ at $400^{\circ} \mathrm{C}$ showing some spheroidization of the $\alpha$ and B2-ordered phases. 

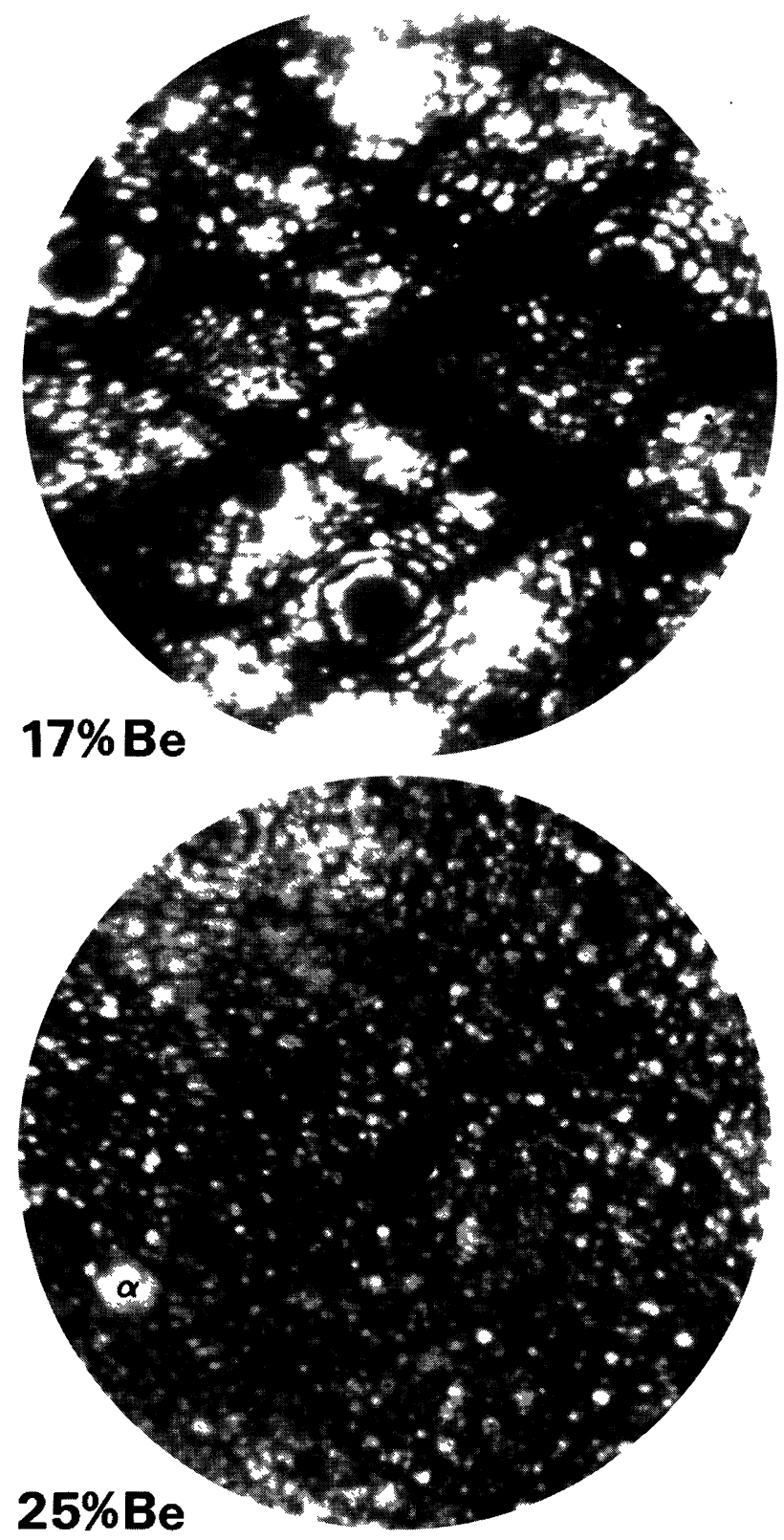

Fig. 6. - Field ion micrographs of the 17 and $25 \%$ Be alloys aged for $2 \mathrm{~h}$ at $429^{\circ} \mathrm{C}$ showing the modulated $\alpha$ and B2-ordered phase microstructure and an isolated brightly-imaging particle of the iron-rich $\alpha$ phase, respectively.

for the B2-ordered phase and the lowest beryllium value for the iron-rich phase (indicated by bold values in Table I) denote the maximum difference in the measured compositions. However, these values should define the minimum extent (with respect to the metastable equilibrium values) of the miscibility gap at each temperature and are plotted as the fitted circles in figure 1 . However, 
the subsequent decomposition of the modulated microstructure into the iron-rich ferrite and the B32-ordered phase prohibits an accurate estimate of the maximum extent of the miscibility gap. It is likely that the results for the $\mathrm{Fe}-25 \% \mathrm{Be}$ material aged for $114 \mathrm{~h}$ at $300^{\circ} \mathrm{C}$ are underestimates of the extent of the miscibility gap due to the slow diffusion of the elements at this low temperature.

Table I. - Summmary of some selected area atom probe analyses of the compositions of the iron-rich and beryllium-enriched B2-ordered phases of the modulated microstructure. Beryllium concentrations are given in atomic percent and the balance of these analyses is iron. Bold values are conservative estimates of the extent of the miscibility gap.

\begin{tabular}{|c|c|c|c|}
\hline \multirow[b]{2}{*}{ Alloy } & \multirow[b]{2}{*}{$\begin{array}{l}\text { Aging Time and } \\
\text { Temperature }\end{array}$} & \multicolumn{2}{|c|}{ Beryllium Concentration } \\
\hline & & $\begin{array}{l}\text { Iron-rich } \\
\alpha \text { phase } \\
\end{array}$ & $\begin{array}{l}\text { Beryllium-enriched } \\
\text { B2-ordered phase }\end{array}$ \\
\hline $\mathrm{Fe}-17 \% \mathrm{Be}$ & $2 \mathrm{~h}$ at $429^{\circ} \mathrm{C}$ & $\begin{array}{c}5.2 \pm 0.8 \\
5.3 \pm 0.7\end{array}$ & $\begin{array}{c}25.8 \pm 2.6 \\
26.0 \pm 2.3\end{array}$ \\
\hline $\mathrm{Fe}-25 \% \mathrm{Be}$ & $4 \mathrm{~h}$ at $400^{\circ} \mathrm{C}$ & $\begin{array}{c}3.1 \pm 0.6 \\
8.0 \pm 0.6\end{array}$ & $\begin{array}{c}27.1 \pm 2.0 \\
29.7 \pm 2.1 \\
29.9 \pm 1.4 \\
30.6 \pm 0.7 \\
\mathbf{3 4 . 1} \pm \mathbf{1 . 6}\end{array}$ \\
\hline $\mathrm{Fe}-25 \% \mathrm{Be}$ & $149 \mathrm{~h}$ at $350^{\circ} \mathrm{C}$ & $\begin{array}{c}2.5 \pm \mathbf{0 . 5} \\
3.2 \pm 0.5 \\
3.3 \pm 0.3 \\
3.4 \pm 1.3 \\
3.3 \pm 0.8\end{array}$ & $\begin{array}{c}34.9 \pm 1.4 \\
38.9 \pm 2.3 \\
40.6 \pm 2.1 \\
43.8 \pm 2.5 \\
\mathbf{4 6 . 8} \pm \mathbf{2 . 8}\end{array}$ \\
\hline $\mathrm{Fe}-25 \% \mathrm{Be}$ & $114 \mathrm{~h}$ at $300^{\circ} \mathrm{C}$ & $\begin{array}{c}3.4 \pm 1.2 \\
3.8 \pm 1.2 \\
4.7 \pm 1.1 \\
5.1 \pm 1.6 \\
5.6 \pm 1.2\end{array}$ & $\begin{array}{c}34.4 \pm 2.9 \\
36.8 \pm 2.4 \\
37.6 \pm 2.2 \\
42.5 \pm 3.0 \\
\mathbf{4 2 . 7} \pm \mathbf{2 . 2}\end{array}$ \\
\hline
\end{tabular}

These atom probe composition determinations indicate that the width of the miscibility gap is significantly wider than proposed by Higgins et al. and approaches almost pure iron and equiatomic FeBe at the lower temperatures. The results are in agreement with the phase diagram of Higgins et al. in that the miscibility gap is not symmetrical about the $25 \%$ Be concentration at the higher temperatures and the critical temperature is skewed to a lower beryllium concentration. This asymmetry is supported by the measured compositions of the two phases and the observation that the $25 \%$ Be alloy aged at $429^{\circ} \mathrm{C}$ only revealed an extremely small amount of decomposition whereas, the $17 \%$ alloy exhibited significant volume fractions of both phases.

AGING BEHAVIOR. - Variations in the extent of phase separation with aging time was investigated from the random area analyses. The results of the statistical analyses of the beryllium concentration fluctuations obtained from the random obtained from the random area analyses in terms of the $P_{\mathrm{a}}$, square wave and Gaussian models are summarized in tables II, III and IV, respectively. In agreement with the data from the field ion images, the atom probe results indicated that even at the shortest aging times, significant phase decomposition had occurred. The goodness of fits between the experimental frequency distributions and the probability distributions determined 


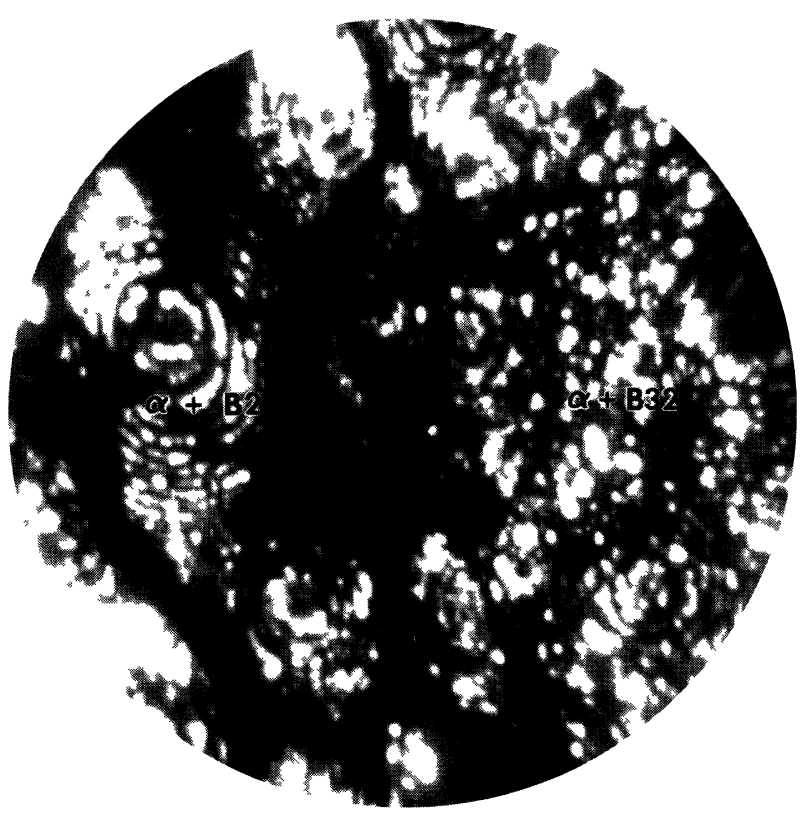

Fig. 7. - Field ion micrograph of the Fe-25\% Be alloy aged for $149 \mathrm{~h}$ at $350^{\circ} \mathrm{C}$ showing regions of the modulated $\alpha$ and B2-ordered phase microstructure and the iron-rich phase and B32-ordered microstructure.

by the best fits of the various models to the experimental data were investigated by standard $\chi^{2}$ tests. Inspection of the $\chi^{2}$ values indicated that no one model was clearly superior to the others, although the $\chi^{2}$ values from the Gaussian model were always slightly lower than those from the square wave model. The $\mu_{1}, \mu_{2}, \Delta c$ and $a_{1}$ results from the square wave and the Gaussian models yielded values that were in close agreement to each other. However, the $\Delta c$ parameters from the $P_{\mathrm{a}}$ model were consistently larger than from the other models. In the square wave model, the values of the volume fractions, $a_{1}$, determined from the applications of the lever rule to the fitted mean concentrations of the two phases and the mean concentrations of the analyses were identical to the values estimated as independent fitting parameters.

Although there was significant scatter in the data, the results from material aged at $400^{\circ} \mathrm{C}$ revealed a slight decrease in the beryllium concentration in the $\alpha$ phase (i.e. $\mu_{1}$ ) and small increases in the beryllium concentration of the B2-ordered phase (i.e. $\mu_{2}$ ) and the $\Delta c$ parameter. Similar, but slightly larger, trends were observed in the material aged at $350^{\circ} \mathrm{C}$ up to $32 \mathrm{~h}$ aging time. The time exponents, a, obtained by fitting these various parameters to a $t^{a}$ power law are shown in table $\mathrm{V}$ together with the goodness of fit parameters, $R$. These results indicate that there was good agreement between the three models for the time exponent determined from the $\Delta c$ parameters; the time exponent for the $\mathrm{Fe}-25 \%$ Be alloy aged between 2 and $149 \mathrm{~h}$ at $350^{\circ} \mathrm{C}$ varied between 0.18 and 0.19 and for the alloy aged for 0.3 to $4 \mathrm{~h}$ at $400^{\circ} \mathrm{C}$ it varied between 0.08 and 0.13 . Similar results were obtained at $400^{\circ} \mathrm{C}$ if the longest aging time was omitted from the regression, whereas at $350^{\circ} \mathrm{C}$ there were significant increases in the time exponents together with improvements in the goodness of fit parameter indicating that there was a discontinuity in the aging behavior and the compositions of the phases had reached a steady state value before $149 \mathrm{~h}$. For the $350{ }^{\circ} \mathrm{C}$ aging temperature, the beryllium-enriched phase $\left(\mu_{2}\right)$ was found to increase in beryllium at a significantly slower rate $(a=0.07$ to 0.08$)$ than the iron-rich phase $\left(\mu_{1}\right)$ was found to deplete in 
Table II. - The results of statistical analysis of the random area analyses of the various heat treatments of the $25 \%$ Be alloy based on the $P_{a}$ model. The parameter $P_{a}$, its standard error and $\Delta c$ are given in atomic percent.

\begin{tabular}{|c|c|c|c|c|c|}
\hline $\begin{array}{c}\text { Aging Time and } \\
\text { Temperature }\end{array}$ & $\mathrm{P}_{\mathrm{a}}$ & $\begin{array}{c}\text { standard } \\
\text { error }\end{array}$ & $\chi^{2}$ & $\begin{array}{c}\text { degrees of } \\
\text { freedom }\end{array}$ & $\Delta \mathrm{c}=2 \mathrm{P}_{\mathrm{a}}$ \\
\hline $100 \mathrm{~h}$ at $300^{\circ} \mathrm{C}$ & 19.1 & 0.6 & 20.8 & 14 & 38.2 \\
& & & & & \\
$2 \mathrm{~h}$ at $350^{\circ} \mathrm{C}$ & 7.6 & 0.4 & 4.5 & 8 & 15.2 \\
$8 \mathrm{~h}$ at $350^{\circ} \mathrm{C}$ & 10.6 & 0.6 & 9.0 & 10 & 21.2 \\
$32 \mathrm{~h}$ at $350^{\circ} \mathrm{C}$ & 22.9 & 0.3 & 54.4 & 17 & 45.8 \\
$149 \mathrm{~h}$ at $350^{\circ} \mathrm{C}$ & 13.9 & 0.3 & 119.7 & 10 & 27.8 \\
& & & & & \\
$0.3 \mathrm{~h}$ at $400^{\circ} \mathrm{C}$ & 10.3 & 0.5 & 13.8 & 12 & 20.6 \\
$1 \mathrm{~h}$ at $400^{\circ} \mathrm{C}$ & 9.8 & 0.4 & 23.2 & 11 & 19.6 \\
$2 \mathrm{~h}$ at $400^{\circ} \mathrm{C}$ & 11.6 & 0.5 & 75.2 & 12 & 23.2 \\
$4 \mathrm{~h}$ at $400^{\circ} \mathrm{C}$ & 12.4 & 0.5 & 25.9 & 12 & 24.6 \\
\hline
\end{tabular}

Table III. - The results of statistical analysis of the random area analyses of the various heat treatments of the $25 \%$ Be alloy based on the square wave model. The parameters $\mu_{1}, \mu_{2}$, and $\Delta c$ are given in atomic percent.

\begin{tabular}{|c|c|c|c|c|c|c|}
\hline $\begin{array}{c}\text { Aging Time and } \\
\text { Temperature }\end{array}$ & $\begin{array}{c}\mu_{1} \\
\alpha \text { phase }\end{array}$ & $\begin{array}{c}\mu_{2} \\
\text { B2-ordered } \\
\text { phase }\end{array}$ & $\begin{array}{c}\mathrm{a}_{1} \\
\text { parameter }\end{array}$ & $\chi^{2}$ & $\begin{array}{c}\text { degrees of } \\
\text { freedom }\end{array}$ & $\Delta \mathrm{c}=\mu_{2}-\mu_{1}$ \\
\hline $100 \mathrm{~h}$ at $300^{\circ} \mathrm{C}$ & 9.5 & 33.4 & 0.34 & 27.8 & 14 & 23.9 \\
& & & & & & \\
$2 \mathrm{~h}$ at $350^{\circ} \mathrm{C}$ & 13.7 & 27.9 & 0.84 & 14.9 & 12 & 14.2. \\
$8 \mathrm{~h}$ at $350^{\circ} \mathrm{C}$ & 13.7 & 28.1 & 0.59 & 10.7 & 12 & 14.4 \\
$32 \mathrm{~h}$ at $350^{\circ} \mathrm{C}$ & 11.0 & 39.0 & 0.41 & 226. & 17 & 28.0 \\
$149 \mathrm{~h}$ at $350^{\circ} \mathrm{C}$ & 8.4 & 36.3 & 0.68 & 43.8 & 15 & 27.9 \\
& & & & & & \\
$0.3 \mathrm{~h}$ at $400^{\circ} \mathrm{C}$ & 16.8 & 30.4 & 0.38 & 9.8 & 14 & 13.6 \\
$1 \mathrm{~h}$ at $400^{\circ} \mathrm{C}$ & 14.1 & 26.8 & 0.45 & 27.5 & 13 & 12.4 \\
$2 \mathrm{~h}$ at $400^{\circ} \mathrm{C}$ & 10.1 & 27.1 & 0.22 & 14.9 & 13 & 17.0 \\
$4 \mathrm{~h}$ at $400^{\circ} \mathrm{C}$ & 12.8 & 29.1 & 0.35 & 6.6 & 14 & 16.3 \\
\hline
\end{tabular}

beryllium ( $a=-0.11$ to -0.19 ). At $400^{\circ} \mathrm{C}$, there was virtually no change in the beryllium content of the beryllium-enriched phase $(a=-0.02)$. This trend is consistent with the location of the alloy within the miscibility gap (i.e. there is a larger concentration difference between the nominal composition of the alloy and the iron-rich boundary than the beryllium-enriched boundary). This behavior also indicated that the majority of the contribution to the $\Delta c$ parameters was from the change in composition of the iron-rich $\alpha$ phase. It is important to note that the compositions of the phases are changing as the scale of the modulated microstructure is coarsening. 
Table IV. - The results of statistical analysis of the random area analyses of the various heat treatments of the $25 \%$ Be alloy based on the Gaussian model. The parameters $\mu_{1}, \mu_{2}, \sigma$ and $\Delta c$ are given in atomic percent.

\begin{tabular}{|c|c|c|c|c|c|c|c|}
\hline $\begin{array}{c}\text { Aging Time and } \\
\text { Temperature }\end{array}$ & $\begin{array}{c}\mu_{1} \\
\alpha \text { phase }\end{array}$ & $\begin{array}{c}\mu_{2} \\
\text { B2-ordered } \\
\text { phase }\end{array}$ & $\sigma$ & $\begin{array}{c}\mathrm{a}_{1} \\
\text { (lever } \\
\text { rule) }\end{array}$ & $\chi^{2}$ & $\begin{array}{c}\text { degrees } \\
\text { of } \\
\text { freedom }\end{array}$ & $\Delta \mathrm{c}=\mu_{2}-\mu_{1}$ \\
\hline $100 \mathrm{~h}$ at $300^{\circ} \mathrm{C}$ & 11.4 & 34.1 & 4.4 & 0.39 & 20.6 & 15 & 22.7 \\
& & & & & & & \\
$2 \mathrm{~h}$ at $350^{\circ} \mathrm{C}$ & 13.8 & 28.2 & 1.2 & 0.85 & 13.8 & 12 & 14.4 \\
$8 \mathrm{~h}$ at $350^{\circ} \mathrm{C}$ & 14.2 & 28.2 & 2.3 & 0.61 & 9.3 & 12 & 15.5 \\
$32 \mathrm{~h}$ at $350^{\circ} \mathrm{C}$ & 12.6 & 39.7 & 5.5 & 0.44 & 86.8 & 18 & 27.1 \\
$149 \mathrm{~h}$ at $350^{\circ} \mathrm{C}$ & 8.5 & 36.4 & 1.2 & 0.69 & 36.6 & 15 & 27.9 \\
& & & & & & & \\
$0.3 \mathrm{~h}$ at $400^{\circ} \mathrm{C}$ & 17.5 & 30.1 & 3.2 & 0.38 & 7.5 & 14 & 12.6 \\
$1 \mathrm{~h}$ at $400^{\circ} \mathrm{C}$ & 15.0 & 26.6 & 2.6 & 0.47 & 24.2 & 13 & 11.6 \\
$2 \mathrm{~h}$ at $400^{\circ} \mathrm{C}$ & 10.5 & 27.0 & 1.9 & 0.22 & 12.3 & 13 & 16.5 \\
$4 \mathrm{~h}$ at $400^{\circ} \mathrm{C}$ & 12.8 & 29.1 & 0.3 & 0.36 & 6.1 & 14 & 16.3 \\
\hline
\end{tabular}

Table V. - Aging exponents determined from the atom probe results for the $\mathrm{Fe}-25 \% \mathrm{Be}$ alloy aged at 350 and $400{ }^{\circ} \mathrm{C}$. The first set of results at each temperature is for the full aging times investigated and the second set of results excludes the longest aging time.

\begin{tabular}{|c|c|c|c|c|c|c|c|c|}
\hline \multirow{2}{*}{ Temperature } & $\begin{array}{c}\text { Time Exponent } \\
\text { and } \\
\text { Goodness of Fit }\end{array}$ & $\begin{array}{c}\mathrm{P}_{\mathrm{a}} \\
\text { Model }\end{array}$ & \multicolumn{3}{|c|}{ Square Wave Model } & \multicolumn{3}{|c|}{ Gaussian Model } \\
\cline { 3 - 9 } & & $\Delta \mathrm{c}$ & $\mu_{1}$ & $\mu_{2}$ & $\Delta \mathrm{c}$ & $\mu_{1}$ & $\mu_{2}$ & $\Delta \mathrm{c}$ \\
\hline $350^{\circ} \mathrm{C}$ & $\mathrm{a}(2$ to $149 \mathrm{~h})$ & 0.18 & -0.19 & 0.08 & 0.19 & -0.11 & 0.07 & 0.18 \\
& $\mathrm{R}$ & 0.52 & 0.93 & 0.80 & 0.88 & 0.84 & 0.76 & 0.91 \\
& $\mathrm{a}(2$ to $32 \mathrm{~h})$ & 0.39 & -0.08 & 0.12 & 0.24 & -0.03 & 0.12 & 0.22 \\
& $\mathrm{R}$ & 0.98 & 0.85 & 0.89 & 0.92 & 0.71 & 0.89 & 0.93 \\
\hline $400^{\circ} \mathrm{C}$ & $\mathrm{a}(0.3$ to $4 \mathrm{~h})$ & 0.08 & -0.15 & -0.02 & 0.10 & -0.16 & -0.02 & 0.13 \\
& $\mathrm{R}$ & 0.83 & 0.80 & 0.39 & 0.74 & 0.84 & 0.32 & 0.79 \\
& $\mathrm{a}(0.3$ to $2 \mathrm{~h})$ & 0.05 & -0.27 & -0.06 & 0.10 & -0.27 & -0.06 & 0.13 \\
& $\mathrm{R}$ & 0.61 & 0.95 & 0.90 & 0.68 & 0.94 & 0.89 & 0.68 \\
\hline
\end{tabular}

The composition difference between the two phases was also determined from the selected area atom probe analyses, as shown in table $\mathrm{I}$. These selected area analysis results indicated that the maximum $\Delta c$ was $20.8 \%$ Be after $2 \mathrm{~h}$ at $429^{\circ} \mathrm{C}, 31.0 \%$ Be after $4 \mathrm{~h}$ at $400^{\circ} \mathrm{C}, 44.3 \% \mathrm{Be} 149 \mathrm{~h}$ at $350{ }^{\circ} \mathrm{C}$ and $39.3 \% \mathrm{Be}$ after $114 \mathrm{~h}$ at $300^{\circ} \mathrm{C}$. A comparison of these selected area analysis $\Delta c$ results and those obtained from the deconvolution of the random area analysis data sets revealed that the deconvolution method consistently yielded values that were significantly smaller than the selected area analysis values. However, this difference is not unexpected. In the selected area analysis method, visual information from the field ion image is used to select the center of the two phases where more extreme concentrations would be expected. In the random area analysis method, atoms are collected from a randomly oriented cylinder of material that 1) will 
only occasionally intersect the center of phases, 2) will contain a significant number of blocks where simultaneous sampling of the two phases occurred, and 3) will randomly select the phases. Inspection of the composition profiles revealed that the majority of the difference between the random area and selected area analysis results was due to variations in the composition of the phases. This result supports the data from the selected area analyses that indicated that there was a significant variation in the compositions of the phases. These variations in composition, the increase in the difference in beryllium contents of the phases with aging time, and the high volume fraction of both phases are consistent with spinodal decomposition within the central portion of a low temperature miscibility gap.

\section{Conclusions.}

An estimate of the extent of the low temperature miscibility gap in the iron-rich portion of the iron-beryllium system has been made by atom probe field ion microscopy. The morphology of the two phases produced by spinodal decomposition within this miscibility gap was determined to be a dislocated macrolattice of isolated cuboidal particles of the iron-rich $\alpha$ phase embedded in a matrix of the B2-ordered beryllium-enriched FeBe phase. The variations in the compositions of the $\alpha$ and B2-ordered phases, the increase in the difference in beryllium concentrations of the phases, $\Delta c$, with aging time, and the high volume fraction of both the $\alpha$ and B2-ordered phases are consistent with spinodal decomposition within the central portion of a low temperature miscibility gap.

\section{Acknowledgements.}

The authors would like to thank K.F. Russell for her technical assistance, Drs. M.G. Hetherington, K.B. Alexander and K.O. Bowman for helpful discussions, and Dr. A. Guha of Brush-Wellman for providing the materials used in this study. This research was sponsored by the Division of Materials Sciences, U.S. Department of Energy, under contract DE-AC05-84OR21400 with Martin Marietta Energy Systems, Inc.

\section{References}

[1] HEUBNER U., Arch. Eisen 34 (1963) 547-554.

[2] RichMan R.G. and DAVIES R.H., Trans. AIME 236 (1966) 1551-1557.

[3] HigGins J., NichOLSON R.B. and WILKES P., Acta Metall 22 (1974) 201-217.

[4] MILlER M.K. and SMTth G.D.W., Atom Probe Microanalysis: Principles and Applications to Material Problems (pub. Materials Research Society, Pittsburgh, PA, 1989).

[5] MILLER M.K., BURKE M.G. and BRENNER S.S., J. Microscopy 139 (1985) 41-7.

[6 MILler M.K., BRENNER S.S., BURKE M.G. and SOFFA W.A., Scripta Metall. 18 (1984) 111.

[7] MILlER M.K., BURKE M.G., BRENNER S.S., SOFFA W.A., ALEXANDER K.B. and LAUGHIN D.E., Scripta Metall. 18 (1984) 285-90.

[8] Miller M.K., J. Phys. Colloq. France 47 (1986) C2 493-9.

[9] SASSEN J.M., HETHERINGTON M.G., GODFREY TJ., SMTTH G.D.W., PUMFREY P.H. and AKHURST K.N., Properties of Stainless Steels in elevated Temperature Service, M. Prager Ed. (Publ. by American Society Mechanical Engineers, New York, NY, 1987 p. 65.

[10] Godfrey T.J., HeTherington M.G., SASSEN J.M. and SMITH G.D.W., J. Phys. Colloq. France 49 (1988) C6 421. 
[11] OLSSON D.M., J. Quality Technol. 11 (1979) 153.

[12] OLSSON D.M., J. Quality Technol. 6 (1974) 53.

[13] Miller M.K., BURKe M.G. and BRENNER S.S., J. Phys. Colloq. France 45 (1984) C9 239-244.

[14] Miller M.K. and BURKe M.G., Proc. Phase Transformations' 87, G.W. Lorimer Ed. (pub. Institute of Metals, London, 1988) p. 199. 